\title{
O CONSENSO SOBRE AS POLÍTICAS SOCIAIS NA AMÉRICA LATINA, NEGAÇÃO DA DEMOCRACIA?
}

\author{
BrunoLautier*
}

\begin{abstract}
Durante meio século, as políticas sociais na América Latina foram caracterizadas pelo conflito. Ora, há uns quinze anos que o conflito deu lugar ao consenso, quer ele se refira aos objetivos de redução da pobreza ou aos instrumentos utilizados para isso. Este artigo analisa as origens da expansão das teorias do consenso, em primeiro lugar nos Estados Unidos, e, em seguida, nas organizações internacionais (PNUD, Banco Mundial e outras), e aprofunda um caso particular, o do consenso em torno dos Conditional Cash Transfer Programmes/Programas Condicionados de Trasnferência de Renda, como meio privilegiado face às políticas focalizadas de combate à pobreza. Ao contrário do que afirmam os defensores do consenso, que veem nele um modo de decisão de ganho mútuo, a conclusão do presente artigo defende a tese segundo a qual a generalizaçã̃o da busca do consenso leva à extinção da democracia.

Palavras-chave: Consenso, Programas Condicionados de Transferência de Renda, Consensus Building, democracia, políticas sociais.
\end{abstract}

Desde o Consenso de Washington, a palavra "consenso" invadiu o discurso sobre o desenvolvimento, especialmente em matéria de combate à pobreza e de políticas sociais. Esses consensos são geralmente mundiais, porém emanam, na sua maioria, de organizações internacionais (Banco Mundial, PNUD, outras agências da ONU). Eles trazem geralmente o nome da cidade onde se realizou uma conferência-Monterrey, Cairo, Beijing, Copenhague - e tratam de objetivos, compromissos, instrumentos. Os consensos são afirmados de modo solene, mas raramente definitivos, já que devem ser renovados, modificados, e até mesmo negar os antecessores.

Se o uso da palavra é repetitivo e ritualizado, seu sentido e a história da sua força raramente são explicitados. Essa explicitação é o objeto do presente texto, que se apoiará particularmente no exemplo dos consensos em torno das políticas * Doutor de Estado em Economia pela Universidade ParisDauphine. Professeur des Universités, em Sociologia, do Institut d'Etude du Développement Economique et Social (IEDES), Universidade Paris 1, Panthéon-Sorbonne. Université de Paris 1 (Panthéon-Sorbonne), 45 bis avenue de la Belle Gabrielle, 94736, Nogent sur Marne, France. bruno.lautier@noos.fr

Tradução de Michel Colin com revisão de Anete Ivo. Os trechos em inglês foram traduzidos por Permínio Ferreira. sociais na América Latina. O artigo tratará de cinco pontos, sucessivamente. Em primeiro lugar, uma introdução onde sintetizo a passagem do conflito ao consenso na elaboração das políticas sociais na América Latina. Em segundo lugar, reexaminarei o aparecimento do que se chama o consensus building. Num terceiro ponto, farei algumas observações sobre a importância do consensus building nas instituições internacionais. No quarto ponto, analisarei um exemplo específico de consenso: aquele que diz respeito aos conditional cash tranfer programmes/programas de transferência de renda condicionada (CCTP) na América Latina. E, na conclusão, farei algumas observações sobre a relação entre consenso e democracia.

\section{DO CONFLITO AO CONSENSO}

No passado (dos anos 1940 a meados dos anos 1990), as políticas sociais, na América Latina como em todos os lugares, foram objeto de debates e conflitos. A implantação das políticas de seguridade social para os assalariados em geral, na segunda metade dos anos 1940, foi muito 
conflituosa em todos os lugares. O conflito situava-se, em geral, no seio das classes dominantes, uma parte das quais aliou-se aos sindicatos. Durante meio século, os debates sobre o grau de universalização do acesso às prestações, o esfacelamento ou, ao contrário, a necessidade de unificar os regimes de seguridade social foram muito intensos, no conjunto dos países. Poderíamos fazer a mesma observação em relação às medidas assistenciais: sua instrumentalização clientelista foi negada por uns e denunciada por outros, sua eficácia proclamada ou questionada, como no caso das subvenções de produtos de primeira necessidade. E, evidentemente, o custo das políticas sociais, por toda parte, foi constantemente objeto de debates muito intensos, sendo as despesas sociais vistas por uns como um elemento necessário às políticas de desenvolvimento ou um produto de uma exigência moral ou religiosa, ou sendo denunciadas por outros pelo seu custo, sua ineficácia ou sua inadaptação às economias pouco desenvolvidas.

Esses debates e conflitos não se resumem a uma oposição entre esquerda e direita, nem mesmo à oposição clássica, na história política latinoamericana, entre liberais e conservadores, mesmo se, em geral, os liberais, quando estiveram no poder, tenham promovido mais políticas sociais que os conservadores. A oposição entre democracia e autoritarismo tampouco possui grande poder explicativo: por um lado, os sistemas de seguros foram instalados, em geral, em períodos pouco democráticos, por líderes geralmente qualificados como populistas (Perón, Vargas, Cárdenas, etc.). Mas foi também nos períodos de forte autoritarismo que se presenciou grande redução das despesas sociais (o Chile de Pinochet não é o primeiro exemplo disso). E, se os períodos democráticos são acompanhados, na maioria vezes, por um crescimento das despesas sociais, isso não acontece quando a situação econômica é desfavorável, como na crise da dívida no início dos anos $1980 .{ }^{1} \mathrm{Du}-$

${ }^{1}$ Filgueira (2005, p. 6 e 7) escreve: “... a evidência reforça o argumento segundo o qual o motor principal do Estado social não é o político, mas o econômico. De fato, a relação entre o PIB e a parte do PIB consagrada às despesas sociais é muito mais robusta que a relação entre democracia e a parte do PIB consagrada às despesas soci- rante esse meio século, as políticas sociais significam mais que uma questão política relevante: elas estão no cerne do campo político, que se compõe e recompõe em torno delas. As quatro maiores patologias políticas do continente-o populismo, o corporativismo, o clientelismo e a corrupção estão estreitamente imbricadas às políticas sociais. Os líderes populistas, ou os partidos hegemônicos (como o PRI mexicano), são acusados da utilização demagógica e eleitoreira dos orçamentos sociais públicos e da delegação da administração dos recursos públicos aos sindicatos, que são denunciadas como se essas concessões visassem a comprar a paz social (a exemplo das obras sociales na Argentina), etc.

O debate sobre as políticas sociais durante meio século é, portanto, permanente do Norte ao Sul do continente. As bases sobre as quais esse debate se desdobra são múltiplas: no âmbito moral (a compaixão para com os miseráveis, ou, ao contrário, a denúncia dos vícios deles como preguiçosos aproveitadores); na economia (o custo das políticas sociais e seu efeito produtivo mediante a formação do capital humano, ou seu efeito sobre a estabilização da demanda); na política (a denúncia da compra dos votos ou a pacificação política produzida pelas políticas sociais).

Ora, esse debate parece perder clareza no início dos anos 1990, acabando por desaparecer no início dos anos 2000. O debate dá lugar a um consenso, que se desdobra em vários campos. Em primeiro lugar quanto aos objetivos que, num pri-

ais”. Mas, considerando certas exceções, ele acrescenta: "Onde a democracia sobreviveu por períodos relativamente longos, a despesa social, ao final de 30 anos, era claramente superior ao que se poderia ter esperado em função do nível do PIB. Inversamente, onde a democracia era fraca ou inexistente, entre os anos 1950 e 1970, a despesa social é inferior ao que se poderia esperar em função do nível do PIB, mesmo trinta anos depois". Essa hipótese dos efeitos de longo prazo de situações democráticas é, ao mesmo tempo, sedutora e contestável. De fato, a democracia é definida, de modo relativamente sumário, pela ausência de, corporatist and authoritarian rule/regra corporativista e autoritária, o que é, no mínimo, impreciso, e o indicador utilizado é o número "de anos de democracia ininterrupta”, qualquer que seja o período em que se situem esses anos. O que classifica em primeiro lugar, atrás da Costa-Rica, a Colombia, a Venezuela, o Chile e o Uruguai, e coloca no final o México e o Paraguai, o que surpreende (o México, ainda corporativista, tem um índice de 0; o Chile só teria sido não-democrático durante o período pinochetista). Filgueira se baseia nos trabalhos de Przeworski (2000). 
meiro momento, são extremamente gerais e indefinidos: reduzir a pobreza (o objetivo principal do Banco Mundial desde o discurso de seu presidente, Lewis Preston, em 1993); promover os direitos das mulheres; universalizar a proteção social (Banco Mundial desde 1999 e BID desde 2002), etc. Eles se tornam cada vez mais precisos a partir dos Millenium Development Goals/Objetivos do Milênio, ratificados de forma unânime por todos os Estados membros da ONU em setembro de 2000. Gradativamente, esses objetivos foram refinados, em especial como os do Consenso de Copenhague (2004, 2006 e 2008). Em seguida, os consensos tratam dos compromissos assinados solenemente por numerosos chefes de Estado (100 no mínimo, 200 ou mais, se possível), mas nunca mencionam possíveis sanções no caso de descumprimento desses compromissos pelos países. Os consensos trazem, muitas vezes, o nome da cidade em que ocorreu a conferência internacional - Monterrey, Cairo, Beijing, Copenhague -, na esteira do Consenso de Washington, que não tratava das políticas sociais, mesmo que suas consequencias sociais tenham sido imensas. Os consensos concernem, enfim, aos instrumentos a serem privilegiados - a distribuição de alimentos, o microcrédito, os Conditional Cash Transfers/os programas condicionados de transferência de renda...-, que se sucedem sem que sejam explicitadas as razões do abandono dos precedentes. Na realidade, os consensos são raramente definitivos, já que é preciso renová-los, modificá-los, e até mesmo negar os anteriores. ${ }^{2}$

A primeira coisa a observar a respeito desses consensos é que só muito raramente eles têm uma origem interna em um país, nacional: eles são diretamente mundiais, proclamados por uma agência da ONU ou uma assembleia de chefes de Estado, e se impõem nos debates políticos nacionais. Posto que todas as instituições internacionais pro-

\footnotetext{
${ }^{2} \mathrm{O}$ primeiro desses consensos proclamados, o Washington consensus/Consenso de Washington, foi questionado por alguns de seus promotores iniciais, ao fim de dezoito anos. Ver em Serra e Stiglitz (Orgs., 2008), obra que reúne textos de José Antonio Ocampo, Paul Krugman, Dani Rodrik, Joseph Stiglitz, Daniel Cohen, Olivier Blanchard, Deepak Nayyer e John Williamson.
}

clamam que sua primeira meta é reduzir à metade a pobreza extrema até 2015 (o primeiro dos MDG, Objetivos do Milênio), nenhum governo ou partido de oposição, na América Latina ou em qualquer outra parte, ousaria afirmar - evidentemente - que não se preocupa com isso, mesmo quando todos sabem que esse objetivo não será alcançado. Mas isso vale também para consensos menos explícitos, como aquele que declara que o desenvolvimento do microcrédito é a melhor ferramenta para a redução da pobreza feminina. Recorrer ao consenso (exógeno) torna-se, assim, um instrumento de circunscrição, e até mesmo do fim do debate político. E esse argumento é retomado pelos governos latino-americanos que, suspeitos de utilização clientelista das políticas sociais, garantem, ao contrário, a "blindagem eleitoral" dessas políticas (quando da implantação do Progresa, no México, ou do Bolsa Família, no Brasil, por exemplo).

$\mathrm{O}$ apelo ao consenso permite eliminar disparidades e diferenças extremamente importantes. Elas dizem respeito, em primeiro lugar, às histórias nacionais que conduziram à formação de sistemas de proteção social extremamente diferentes em termos de configuração institucional, e às forças políticas que propiciaram o seu nascimento e desenvolvimento, além dos riscos cobertos. Mas elas estão relacionadas também, simplesmente, à sua importância, quer seja avaliada pela despesa pública per capita ${ }^{3}$ ou por qualquer tipo de indicadores qualitativos (como taxa de escolarização, indicadores sanitários, etc.). Quando se está diante de um consenso proclamado sobre um instrumento de políticas sociais, o que é bom para um país seria bom necessariamente para todos.

Apesar do uso da palavra consenso ser repetitivo e ritualizado, seu sentido raramente é explicitado. Um retorno ao estudo da palavra pode ser interessante. O termo consenso tem, de fato,

${ }^{3}$ Em 2004-2005, ela era mais forte na Argentina (com \$ 1.521 de 2.000 per capita) diante do Uruguai (1.087), Cuba (870) e o Brasil (860). Na outra extremidade, encontra-se Honduras, Paraguai, Guatemala, Equador e Nicarágua, entre \$. 120 e 90. A despesa média per capita para a América Latina (expressa em US\$, em valores de 2000) era de \$ 658 em 2004-2005 (Cf. CEPAL,2007, p.106-108). 
uma longa história, de Aristóteles ${ }^{4}$ a Espinosa, Tocqueville, Comte, até a teóricos da psicologia social e a técnicos contemporâneos do consensus building (construindo o consenso). Por falta de espaço, ${ }^{5}$ deixarei de abordar aqui a história da palavra consenso no âmbito da Filosofia ou da Psicologia social. ${ }^{6}$ Tampouco tratarei dos contextos lexicais do seu uso.7 Vou me ater à aplicação dessa palavra em matéria de políticas de desenvolvimento, especialmente das políticas sociais. O uso repetido do termo foi promovido pelos técnicos do consensus building desde o fim dos anos 1980, que apostaram no sentido aparente e imediato do termo (há consenso quando todos estão de acordo) para propor e impor uma visão particular de deliberação e representação políticas. Os promotores do consensus building influenciaram fortemente o Banco Mundial, o PNUD (Programa das Nações Unidas para o Desenvolvimento), o BID (Banco Interamericano de Desenvolvimento) e projetaram-se sobre numerosos governos. O sentido dado à palavra pelos promotores do consensus building se superpõe ao senso comum, carregando todos os estratos de significações históricas agregadas à palavra. Na conclusão deste artigo, veremos que a divergência (ou o desacordo?) prevalece na própria palavra consenso, o que é, ao menos, paradoxal, visto que há consenso sobre tudo, salvo sobre o que seria o consenso. Eé essa divergência que dá força ao discurso das instituições internacionais. Esta análise resultará num exame da função legitimadora dos consensos: sua função não seria a de acabar e proibir o debate, antes mesmo que ele tenha sido iniciado? Em nome de uma evidência moralmente fundada e de uma comunidade de valores nunca verificada, a sua função não seria a de eliminar a questão dos direitos e da democracia do debate sobre as políticas sociais?

\footnotetext{
${ }^{4} \mathrm{O}$ qual não utiliza, evidentemente, a palavra consenso, mas acordo (sumphonia), que, em todos os dicionários, é o primeiro sinônimo da palavra consenso.

${ }^{5}$ Pour un développement, Cf. Lautier (2010).

${ }^{6}$ Cf. Doise e Moscovici (1992); e Lair (2007).

${ }^{7}$ Cf. Martel (2007). O autor analisa, em especial, todos os epítetos que acompanham a palavra consenso: amplo,
} forte, unânime, fraco, tácito, etc.

\section{O CONSENSUS BUILDING}

As teorias contemporâneas do consensus building nasceram nos Estados Unidos, no centro do Public disputes Program da Harvard Law School, e, sobretudo, do Consensus building Institute (CBI) do Massachusetts Institute of Technology (MIT). Esse último, coordenado por especialistas em planejamento territorial, ambientalistas e outros experts, propõe e vende intervenções denominadas de facilitação e mediação para tipos de conflitos $^{8}$ extremamente diversos. É, ao mesmo tempo, uma técnica e um método, mas, provavelmente, também uma filosofia.

O ponto de partida das intervenções do CBI, ao final dos anos 1980, foi uma crítica das Robert's Rules of Order (Regras e ordem de Robert), regras que formalizam os debates de assembleias democráticas, e que foram denunciadas pela sua ineficácia e pelo rancor que produzem nas minorias. Elas foram formalizadas pela primeira vez pelo general Henry Martyn Robert, em 1870, que constatara, quando de suas mudanças sucessivas, a "anarquia" dos debates parlamentares nos parlamentos dos Estados Federados. ${ }^{9}$ Elas foram reformuladas e detalhadas no decorrer de sua vida e depois, sob a égide de seus descendentes (até a 10 a edição, de2000). Essas Robert's rules são essencialmente regras processuais muito detalhadas, sem pretensão filosófica, mas sim de enunciar as regras de funcionamento dos constructive and democratic meetings/encontros democráticos e construtivos. O seu sucesso foi imenso (500.000 exemplares vendidos desde 1915) e perdura até

${ }^{8}$ O CBI fala, em geral, de "disputas" e não de "conflitos". Existe, nos Estados Unidos, um centro, o Beyond Intractability Center, que funciona na Universidade do Colorado (Boulder), nucleado em torno da questão de resolução dos conflitos. Em um artigo publicado pelo Centro de Boulder, intitulado "The difference Between 'Conflicts' and 'Disputes'”, Brad Spangler e Heidi Burgess (The conflict Resolution Information source, CR-Info version IV, july 2003) definem as disputas, como short term disagreements that are relatively easy to resolv (pequenos desacordos que são relativamente fáceis de resolver); enquanto os conflitos são os long-term, deep-rooted problems that involve seemingly non-negotiable issues and are resistant to resolutio (problemas profundamente enraizados e de longo prazo, resistentes à resolução).

${ }^{9}$ Cf. abundante documentação disponível no site: www.robertsrules.com/history. 
os dias de hoje. Elas são constantemente ampliadas e reeditadas pelos herdeiros do general Robert. Nelas encontram-se, em detalhes, todas as regras concernentes à conduta das assembleias: ordem e duração dos tempos do pronunciamento; emendas; ponto de ordem; moções; suspensão de sessão, etc. O objetivo exposto é obter maiorias legítimas e incontestáveis, e isso só é possível se for garantida a uma strong minority (forte minoria) a possibilidade de impor à maioria uma discussão sobre os assuntos que ela demanda. Consideramse apenas as minorias que se manifestam. Como escreve Robert: "Silence mean consent"|"Silêncio significa consentimento". O que poderia ser traduzido assim: "Quem cala consente".

A discussão sobre o caráter democrático ou não dessas regras de funcionamento das assembleias foi constante, desde o início do século XX. Sua crítica levou ao aparecimento das tecnicas de consensus building. Na apresentação de uma obra recente de Lawrence Susskind, fundador do Consensus Building Institute, intitulado Breaking Robert's Rules of Order ${ }^{10} /$ Rompendo com as regras e ordem de Robert, podemos ler: "Está na hora de acabar com as regras. Convertam-se a este novo modo de conduzir suas reuniões, de construir o consenso e de alcançar resultados". Cada dia, grupos de todo tipo tentam chegar a acordos utilizando as Robert's Rules of order. Esses rituais esotéricos - conhecidos também como protocolo parlamentar - produzem, em geral, uma maioria vitoriosa e uma minoria insatisfeita, que só para de lutar quando obtém o que deseja. Em realidade, as decisões provenientes da regra majoritária são intrinsecamente instáveis e geralmente produzem resultados bem menos satisfatórios do que se todos tivessem trabalhado juntos.

Lawrence Susskind, o fundador do CBI, não é um jurista ou um cientista político, mas um especialista em planejamento urbano. Ele começou suas atividades de consultor na área de resolução de conflitos, ligada ao planejamento urbano, no início dos anos 1980: o conflito em torno da

${ }^{10}$ Breaking Robert's Rules (Susskind e Cruikshank, 2006). ampliação do aeroporto de Schipol, nos Países Baixos $^{11} \mathrm{e}$ diferentes conflitos ligados a casos de poluição fluvial ou marítima. Depois, nos anos 1990, as temáticas se diversificaram: prevenção dos acidentes nucleares, direitos dos "Native American”, prevenção da AIDS, aborto, desvios de conduta sexual de membros do clero, regulação da internet, e até mesmo os conflitos de trabalho (em Levi Strauss) etc. Essas atividades de consultor foram realizadas de forma dispersa, até que Lawrence Susskind fundou, em 1993, em Cambrigde, o Consensus Building Institute. Embora ele se refira frequentemente à Universidade de Harvard e ao MIT, o CBI é juridicamente independente e tem um estatuto de "not-for-profit organization/organização sem fins lucrativos"12 Esse Instituto "trabalha com líderes, advogados, peritos e comunidades na promoção de negociações, na construção de consensos e na resolução dos conflitos concretos". Ele tem por objetivo a ajuda e consultoria às agências públicas, aos governos locais e ao nacional, às instituições internacionais e às ONGs. Em sua apresentação na internet, o CBI publica notas intituladas How CBI helps Government Agencies/"Como o CBI ajuda as agências governamentais", onde ele escreve, por exemplo, "we help facilitate the policy making process (...) and implement difficult decisions /"nós ajudamos a facilitar o processo de fazer política [...] e implementar decisões difíceis", e "we help design effective public engagement strategies and mediate disputes/"nós ajudamos a desenhar compromissos públicos estratégicos e mediar conflitos". A linguagem adotada é, assim, relativamente próxima daquela de grande número de escritórios de consultoria, com o detalhe de que os destinatários são organismos públicos: agências governamentais e, principalmente, municipalidades.

Esses trabalhos dos anos 1980 e 1990 são sintetizados em duas obras: Susskind e Field

${ }^{11}$ Caso emblemático e precursor, analisado por Peter Driessen em Susskind et al (1999).

${ }^{12} \mathrm{O}$ outro grande centro de pesquisa sobre as teorias do consensus building nos Estados Unidos é a associação Beyond intractability, que funciona na Universidade de Colorado (Boulder), e é nucleada sobre a questão da resolução dos conflitos (em especial, os conflitos armados). 
(1996) e Susskind et al (1999). A declaração introdutória (p.xvii) desse Handbook de 1.147 páginas não deixa dúvida quanto às ambições do método: "Adotando as abordagens fundadas sobre o consenso, os grupos podem, ao mesmo tempo, desenvolver soluções e tomar decisões mais criativas, gozando de um apoio mais amplo do que aquelas que resultam dos métodos tradicionais, como a tomada de decisão top down ou o protocolo parlamentar". As Robert's Rules são criticadas a partir de dois argumentos principais: essas regras são contraprodutivas, pois elas produzem, em geral, soluções "de senso comum", e acarretam um fraco envolvimento das stakeholders (partes envolvidas), não somente aquelas que são minoritárias (reencontramos o tema da "ditadura da maioria"), mas também daquelas que fazem parte da maioria. Seguem centenas de páginas de metodologia da formação de um consenso: identificação dos objetivos, identificação das partes envolvidas, identificação e conduta dos conflitos, negociação, papel dos mediadores e facilitadores, relações com o poder político e a imprensa, e, finalmente, formulação e avaliação do consenso. Os equívocos do consensus building são denunciados (idem, p.xxxxi). Poder-se-ia resumi-los nas cinco fórmulas: " $\mathrm{Eu}$ vou ter de abandonar minha autoridade"; "eu vou sofrer pressões para trair meus mandantes"; "eu vou perder meu prestígio"; "eu vou ter de ajudar os meus inimigos"; $\mathrm{e}$ "eu vou ser forçado a abandonar meus princípios". E todo o discurso metodológico é ilustrado por umas vinte monografias que relatam, numa boa metade delas, a resolução de conflitos ligados a questões de urbanismo ou do meio ambiente, que surgiram principalmente no final dos anos 1980 e nos anos 1990. Nem os filósofos que escreveram sobre o acordo ou o consenso (Aristóteles, Espinosa, Comte, Durkheim, etc.), nem os autores do public choice são citados.

A biografia dos membros do staff do CBI mostra que, em geral, eles são consultores provenientes de escritórios de consultoria, tendo uma atividade ligada aos grandes investimentos em infraestruturas urbanas ou às questões do meio ambiente, não sendo filósofos, cientistas políticos ou estrategistas. Eles são pouco numerosos (14 "associados" ou “diretores"), não são (ou são pouco) especializados, embora a maioria tenha, geralmente, iniciado sua carreira e seus estudos pelos conflitos ligados às questões ambientais. A propósito de Kate Harvey (associate), leia-se, por exemplo: "Seus centros de interesse são variados e compreendem as políticas ambientais e energéticas, a saúde pública, os movimentos de jovens, o desenvolvimento comunitário e a tomada de decisão nas empresas".

O Consensus Building Institute tem como clientes algumas grandes empresas privadas, umas vinte grandes ONGs, vários ministérios ou Estados Federados estadunidenses, e sua atividade internacional só se desenvolveu verdadeiramente nos anos 2000. No momento, ele se glorifica de colaborar com numerosas fundações (no Canadá, em Israel, no Brasil, nas Filipinas), mas também com organizações internacionais: a OMC (Organização Mundial do Comércio), o Banco Asiático de Desenvolvimento, o State of the World Forum, a Comissão de Desenvolvimento Sustentável das Nações Unidas, o PNUD e o Banco Mundial.

\section{O CONSENSUS BUILDINGE AS ORGANIZA- ÇÕES INTERNACIONAIS}

O Consensus Building Institute não introduziu a palavra consenso no vocabulário das organizações internacionais por uma razão de simples cronologia: o "Consenso de Washington” é anterior à sua criação. Além disso, desde o fim dos anos 1980, várias organizações internacionais começaram a utilizar o termo consenso, sendo a OIT um bom exemplo disso. Não tendo poder regulamentar em matéria de normas sociais internacionais e tendo de conciliar os interesses a priori divergentes, só lhe resta reunir seus três componentes - ou seja, colocá-los juntos -, fazê-los chegar a um consenso e, em seguida, tentar fazer outras instituições (em especial a OMC) aderirem a esse consenso. Foi o método utilizado durante a elaboração da noção de "trabalho decente", sem recorrer, entre- 
tanto, explicitamente ao CBI. ${ }^{13}$

O papel desse Instituto, no entanto, foi considerável, em especial no âmbito do PNUD e do Banco Mundial. No PNUD, o CBI está encarregado, desde o fim dos anos 1990, da formação dos quadros para a "Abordagem de Ganhos Mútuos para a Negociação" (Mutual Gains Approach to Negotiation). 400 quadros do PNUD (em especial os coordenadores residentes) já tinham sido formados até o fim de 2007. No Banco Mundial, certo número de agências instalou sessões de formação e fóruns dedicados ao consensus building. ${ }^{14} \mathrm{E}$ as sessões de formação do Banco Mundial retomam literalmente certos trechos do Manual do CBI. ${ }^{15}$

O consensus building se espalhou em todos os programas do Banco Mundial, particularmente em matéria de meio ambiente ${ }^{16}$ e de luta contra a pobreza. Nesse último campo, a promoção do conceito de consensus building foi formalizada no âmbito do Banco Mundial, por um texto de Paul Collier (2000). Paul Collier, após uma análise crítica das práticas sobre as "condicionalidades" do Banco, localiza as causas de sua ineficiência no nível do político e no das instituições, e escreve: "o consensus-building permite acelerar uma mudança duradoura da política”. Para ele, o consenso permite, bem melhor que o estabelecimento de uma relação de força em torno de condicionalidades, estabilizar o horizonte de médio prazo, e "um consenso político visível é mais eficaz que as condicionalidades para tranquilizar os investidores.” (p.27).

Na Cúpula de Copenhague (1995), preparada principalmente pelo PNUD, estamos aparente-

${ }^{13}$ Cf. Somavia (2004, p.xv): "A parceria de trabalhadores, empregadores e governos continua sendo o aspecto mais essencial da razão de ser da OIT em um mundo do trabalho em constante mutação. Se pontos de vista e interesses contrários tornam muitas vezes as escolhas difíceis, eles conduzem também a compromissos equilibrados. Às vezes, as sensibilidades são vivas, e parece difícil alcançar um consenso". Nicolas Valticos foi um dos principais promotores da ideia de "trabalho decente".

${ }^{14}$ Por exemplo, a International Finance Corporation (membro do World Bank Group) instalou um Global Corporate Governance Forum (e múltiplos fóruns regionais) cujo objeto é "Raising awareness and building consensus./

Aumentar a consciência e construir o consenso".

${ }^{15}$ Ver, por exemplo: Van den Oever (2004).

${ }^{16}$ Ver, por exemplo: Banuri (2008). mente diante de um consenso maximalista. Porém, cinco anos depois, com a extensão do consenso à OCDE, ao BM, ao FMI e a outras agências da ONU, por ocasião da formulação dos "Objetivos do Milênio", em 2000, ${ }^{17}$ o consenso restringiu seu objeto, reduzindo-o a oito objetivos. Em seguida veio o "Consenso de Monterrey"18. O exame do comunicado final ${ }^{19}$ mostra algo notável: a expressão “Consenso de Monterrey” é utilizada várias vezes, mas nunca se diz em que consiste esse consenso. Fala-se de “consagração de uma nova parceria”, da “participação dos países em desenvolvimento nos processos decisórios das instituições internacionais", e, mesmo, de "contrato, como alguns o chamaram". No entanto, não se sabe muito bem entre quem foi formado o consenso: entre as organizações internacionais? Entre elas e os governos dos países do Norte? Entre os governos do Norte e os governos do Sul? Solicita-se claramente a esses últimos "esforços" em matéria de organização dos circuitos financeiros, de "transparência" e de luta contra a corrupção, de liberalização comercial e financeira. E, do outro lado, as organizações internacionais e os governos do Norte "são convidados a” aumentar a APD (Ajuda dos Países Desenvolvidos) até $0,7 \%$ do PIB, melhorar seu encaminhamento, etc.

Por trás do consenso, não há um contrato, mas a consagração de uma assimetria aceita: os financiadores do desenvolvimento são convidados ao exercício da generosidade, sob a contrapartida de um empenho dos ajudados. No entanto, sete anos depois, parece que nenhum país do Norte jamais foi sancionado por não ter dado sua APD em

${ }^{17}$ Formulados na Millennium Declaration adotada por 189 países durante o United Nations Millennium Summit, em Nova Iorque, em 2000. São eles 1. Reduzir a extrema pobreza e a fome. 2. Assegurar a educação básica para todos. 3. Promover a igualdade e a autonomizacão das mulheres. 4. Reduzir a mortalidade infantil. 5. Melhorar e outras enfermidades. 7. Assegurar um meio ambiente sustentável. 8. Instalar uma parceria mundial para o desenvolvimento. A maioria é detalhada em vários "alvos" e acompanhada por indicadores.

${ }^{18}$ Retomadas e sintetizadas em: Goldin, Rogers e Stern (2002).

19 "Conferência internacional sobre o financiamento do desenvolvimento“. Nações Unidas, Departamento da informação, Divisão da informação e das mídias, 22 de março de 2002. 
0,7\% do PIB. O Consenso de Monterrey se tornará rapidamente uma denominação controlada, cujo conteúdo não é preciso mais relembrar, já que o fato se produz apenas por essa denominação. ${ }^{20}$

Após o "Consenso de Monterrey", outro consenso de natureza totalmente diferente apareceu: o “Consenso de Copenhague” (2004). A palavra consenso aqui é utilizada em outro sentido: o de um "acordo" quase-aristotélico entre pessoas iguais e que compartilham um mesmo senso de bem comum e de valores comuns de forma unânime. Trata-se, na realidade, de um consenso entre

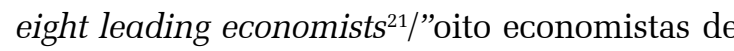
ponta" que-com base em relatórios de especialistas-reuniram-se para hierarquizar dez challenges/ desafios e escolher entre 32 proposals/propostas (ou opportunities)/(ou oportunidades) que permitirão enfrentá-los. A mesma equipe ${ }^{22}$ se reuniu de novo em Copenhague, em 2006 e em maio de 2008 (Copenhagen Consensus, 2008), dessa vez para produzir uma lista das solutions/soluções aos challenges/desafios: em primeiro plano, encontrase a adição de vitamina $\mathrm{A}$ e zinco aos alimentos infantis, e, em segundo plano, a Agenda de desenvolvimento de Doha (Doha development agenda). ${ }^{23}$ A oposição entre as duas formas de consen-

20 Cf. International Bank for Reconstruction and Development, The World Bank (2005) p. xi: ”The $\stackrel{\circ}{\circ}$ Millennium Development Goals (MDGs) and the Monterrey Consensus have created a powerful global $\dot{0}$ for eradicating poverty and related human

The Monterrey Consensus stresses the mutual The Monterrey Consensus stresses the mutual achieving these goals“. Encontra-se, nesse texto, em vários momentos, formulas como: "There is genera consensus on...."/"Existe um consenso geral...", "Broad consensus has emerged that..."/"Um amplo consenso emergiu..." Esse relatório é o primeiro a pôr seriamente em dúvida a possibilidade de se alcançarem os ODM, em especial na Africa subsaariana. No entanto, em nenhum momento ele questiona a noção de consenso, do qual é dito, por outro lado, que era construído sobre areia.

${ }^{21}$ Entre os quais, quatro prêmios Nobel e dois economistas "do Sul", um indo-americano (Jagdish Bhagwati) e um sinoamericano, economista-chefe do Banco Mundial (Justin Yifu Lin).

${ }^{22}$ Com uma diferença apenas de três membros ( $F$. Bourguignon apareceu).

23 A lista completa, que se encontra em: www.copenhagenconsensus.com, é relativamente surpreendente; a "microfinança" é classificada na $22^{a}$ posição, e é uma solução ao challenge/desafio: "woman"; as os "condicional cash transfers"/"transferências condicionadas de renda" estão na $17^{a}$ posição, e dependem do challenge/desafio "educação", etc. so (a de Monterrey e de Copenhague) é clara: por um lado, uma reunião de dezenas de chefes de Estado e de todos os dirigentes das organizações internacionais, numa grande celebração, afirmando um acordo em torno de "valores comuns", essencialmente morais (a solidariedade entre países ricos e pobres), que, evitando empregar explicitamente a palavra "condições", só as impõem a uma das partes. Do outro, um tribunal de oito notáveis (exclusivamente de economistas) reunidos por um alto funcionário dinamarquês e baseados em uns trinta relatórios de peritos, patrocinado pelo governo dinamarquês e o jornal The Economist. É certo que poderíamos ironizar sobre a competência desses "notáveis" em matéria de vitamina A ou de prevenção da malária etc. Mas destaca-se que a impressão que se tem é que essas pessoas são sérias politicamente, não têm nada a perder ou a ganhar pessoalmente e não caem na ênfase oratória. ${ }^{24}$

Os consensos parecem se tornar, doravante, a base de um novo modo de periodização das relações internacionais em matéria de ajuda ao desenvolvimento, como os "ciclos" (ou os rounds) em matéria de comércio internacional. Um consenso encerra o anterior. O “Consenso de Brasília”, oriundo de um encontro dos governos latinoamericanos e das instituições financeiras internacionais, em novembro de $2003,{ }^{25}$ inaugurou uma série de consensos regionais. Rebatizam-se de ex ou pós-consenso, inclusive, declarações anteriores em que a palavra não estava presente, como no caso do "Cairo consensus", denominado assim em 1999 no relatório da UNFPA,$^{26}$ quando, na realidade, o texto assinado por 179 países em 1994, apos a Internacional Conference on Population and Development do Cairo, não faz menção a consenso. Aparecem aqui e acolá confusões e concorrências, como a respeito do "Beijing consensus". De um lado, o jornalista Joshua Cooper Ramo, ao tratar da cooperação Sul-Sul, inventa a palavra, que ele apre-

${ }^{24}$ Lembremo-nos o discurso do Presidente Chirac em Monterrey.

${ }^{25}$ Cf. "Political consensus building: The Brasilia International Conference on the Millennium Development Goals in Latin America and the Caribbean“, Brasília: BID/PNUD/CEPAL/WB, 2003.

${ }^{26}$ UNFPA (1999). 
senta explicitamente como um consenso "emergente", que deve substituir o "Consenso de Washington", amplamente desacreditado. ${ }^{27}$ De outro lado, a FAO populariza o "Consenso de Beijing sobre o futuro da agricultura mundial e das zonas rurais, formulado durante uma reunião de especialistas mundiais em agricultura, meio ambiente e economia, realizada em Beijing nos dias 9 e10 de setembro de $2005 .^{28}$

Os consensos também são "mortais", particularmente o primeiro deles, o Consenso de Washington. Assim, é preciso reconsiderá-los. Stiglitz, em um capítulo intitulado Is there a 'Post-Washington Consensus' Consensus? ${ }^{29}$ escreve: "Se hoje existe um consenso sobre as estratégias a promover nos países pobres, ele só trata de um ponto: que o Consenso de Washington não trouxe resposta". O consenso sobre o fim dos consensos é a última forma de consenso e negação do debate. Ele permite poupar-se dos ridículos e mortíferos processos de autocrítica nos quais o estalinismo se enterrou. O novo consenso não exige nem punição, nem reparação, apenas adesão.

\section{UM EXEMPLO DE FORMAÇÃO DE CONSEN- SO SOBRE AS POLÍTICAS SOCIAIS: OS conditional cash transfer programmes"/ programas de transferência condicional de renda" na América Latina}

O exemplo mais patente de transição acrítica de um consenso ao outro em matéria de políticas sociais na América Latina é a passagem do consenso sobre as políticas focalizadas (em favor dos pobres) para os "conditional cash transfer programs"/ "programas de transferência condicional de renda". As políticas (ultra) focalizadas,

\footnotetext{
${ }^{27}$ Cooper Ramo (2004, p.3-4). Apesar das formulas bombásticas (como "The Beijing consensus offers hope for the world“", p.60) e da exposição de "teoremas” martelados como verdades incontestáveis, não se sabe que se trata de um consenso, senão que ele se opõe ao Consenso de Washington.

${ }^{28}$ http://www.fao.org/newsroom/fr/news/2005/107643/ index.html.

${ }^{29}$ In: Serra e Stiglitz (Orgs.) (2008).
}

implementadas desde o fim dos anos 1980, foram objeto de múltiplas críticas de todos os lados. Mas em nenhum momento houve um consenso crítico. As instituições internacionais (em especial o BID e o Banco Mundial) começaram a fazer avaliações críticas de certas políticas focalizadas a partir de 1997-98, mas não uma crítica global: criticamse mais os erros da focalização, especificamente o fato de muitos não-pobres receberem ajuda, e muito menos o fato de numerosos pobres não a receberem; critica-se a incitação à dependência e um fechamento nas "armadilhas da pobreza". Paralelamente, e, ao mesmo tempo, assiste-se ao crescimento da influência de Amartya Sen, de suas ideias e de seu vocabulário (capabilities/capacidades, empowerment/empoderamento, etc.). ${ }^{30}$ Uma das evidências foi a substituição do vocabulário das instituições internacionais, que passaram do "combate à pobreza" ao "combate à vulnerabilidade". Além de sua definição técnica ou estatística, a vulnerabilidade indica uma mudança de abordagem: passa-se da compaixão vitimizante (o pobre que se ajuda) à atenção paternal (o vulneravel que é ajudado a ajudar-se, e é protegido enquanto continuar frágil).

O elemento mais significativo dessa mudança foi a invenção, a multiplicação e a popularização dos CCTP (Conditional Cash Transfer Programs/ Programas de Transferência Condicional de Renda). ${ }^{31}$ Eles nasceram, em sua versão moderna, no México, com o Plano PROGRESA (1997), transformado em 2002 em Oportunidad. Depois, foram

${ }^{30}$ A. Sen recebeu o Prêmio Nobel de economia em 1998, e foi o convidado de honra da ABCD (Annual Bank Conference on Development) do Banco Mundial em 1999, o que encerra, em grande parte, o conflito entre essa instituição e o PNUD, objetivando os indicadores de desenvolvimento, mas também a legitimidade da intervenção social do Estado.

${ }^{31}$ Não devemos nos esquecer, entretanto, de que o Brasil instalou, no fim de 1993 o BPC (Benefício de Prestação Continuada), que é, de fato, uma transferência condicional de renda destinada às pessoas idosas e portadores de deficiência, integrantes de famílias com um limite de renda média per capita inferior a um quarto de salário mínimo. O montante da alocação é igual a um salário mínimo. Esse programa é o mais importante programa brasileiro de transferência de renda em volume (o segundo, após o Bolsa Família, em número de pessoas inseridas). No fim de 2005, 1,1 milhão de portadores de deficiência e 1,6 milhão de pessoas idosas recebiam essa alocação, cujo custo representa aproximadamente $9 \%$ das despesas de proteção social. 
instalados os programas JJHD (Chefas e chefes de família sem emprego) e Familias por la Inclusion Social na Argentina, o Chile Solidario no Chile (2002), o Bolsa Família, no Brasil (2003) e o Familias en acción na Colombia (2001), e em uns dez outros países. ${ }^{32}$ Seu princípio geral ${ }^{33}$ é que se trata de transferências monetárias (agrupando alocações de desemprego, escolaridade, alimentação), instaurando um complemento de renda familiar mínima. $\mathrm{O}$ conteúdo assistencial dos programas é acompanhado por objetivos de promoção individual, ditos de "desenvolvimento humano" ou de "formação de capital humano". A ajuda social é condicionada a contraprestações por parte dos beneficiários, no âmbito dos deveres familiares em matéria de saúde e de escolarização: a frequencia escolar (em geral, um mínimo de 85\% de presença), controles de saúde (em especial, mas não unicamente, crianças e mulheres grávidas) e, às vezes (Chile, Panamá), entrevistas obrigatórias com psicólogos ou assistentes sociais. ${ }^{34}$

A porcentagem da população atingida é extremamente variável: ${ }^{35}$ muito elevada nos dois países mais midiatizados nesses programas (25\% no México, 22\% no Brasil), mas ela não passa de 10\% em qualquer outro país, mesmo naqueles nos quais os índices de pobreza são os mais elevados (como 3,6\% no Peru, 2,7\% na Nicarágua, por exemplo). Porém, mesmo quando o número de beneficiários

${ }^{32}$ Costa Rica, Equador, Honduras, Jamaica, Nicarágua, Panamá, Paraguai, Peru, República Dominicana, El Salvador, Uruguai. Encontra-se, no texto de Enrique Valencia (2008), uma apresentação e numerosos detalhes sobre esses planos. Ver, igualmente, o Panorama Social da América Latina 2007 (CEPAL, p.132-133) e o Panorama Social da América Latina 2009 (CEPAL cap.2, p.35-47). A obra, que sintetiza as avaliações dos CCTP para o Banco Mundial (Fizbein e Schady, 2009), não é exclusivamente consagrada à América Latina, mas aproximadamente $2 / 3$ dos exemplos analisados são provenientes desse continente.

${ }^{33}$ Para mais detalhes, ver: Ceballos e Lautier (2007).

${ }^{34}$ O PJJHD, criado na Argentina em 2002, tinha um aspecto nitidamente de workfare, já que a primeira condição para as alocações era a participação em empregos de emergência. Mas o fato de cada vez mais os beneficiários serem totalmente "inempregáveis" levou à criação, em 2006, do programa "Familias", que é um CCTP “clássico”, e a transferência progressiva dos beneficiários de um para outro. Desde 2007, a CEPAL não considera mais o programa JJHD entre os CCTP.

${ }^{35}$ Os números, extraídos do Panorama social de América Latina CEPAL (2007) datam de 2005 ou 2006, de acordo com os países. é elevado, o custo total dessas transferências permanece muito baixo $(0,43 \%$ do PIB no México, assim como no Brasil), o que é um indicador do baixíssimo nível para as prestações individuais.

Todos esses CCTP são muito elogiados pelas instituições internacionais, notadamente o Banco Mundial e o BID. No entanto, esse entusiasmo não se baseia na consecução dos objetivos últimos, que são de longo prazo e relativos à saída da pobreza e à melhoria do bem-estar, os quais, por enquanto, não são nem observáveis nem mensuráveis. ${ }^{36}$ No curto prazo, a pobreza diminui muito pouco: no México, o impacto de ProgresaOportunidad, em matéria de redução da pobreza, é de $2 \%$ em meio rural e de $7 \%$ em meio urbano, em 2005. ${ }^{37}$ Em compensação, visto que o teto de recursos que dá direito ao benefício é muito baixo, a pobreza extrema diminui muito mais, ${ }^{38}$ assim como, por conseguinte, a "brecha da pobreza", ou seja, a distância entre a renda média dos pobres e a linha da pobreza utilizada.

O consenso em favor dos CCTP se formou muito rapidamente: apesar do Progresa só ter três anos, em 2000, foi publicada uma primeira avaliação (entusiasta) pelo International Food Policy Research Institute (IFPRI), organismo privado sediado em Washington. Os meios acadêmicos engrenaram-se rapidamente neles (as primeiras publicações datam de 2003), e os bancos de desenvolvimento (Banco Mundial e Banco Interamericano de Desenvolvimento), igualmente

${ }^{36}$ Ver artigo de E. Valencia, (2008): "No que concerne à redução da pobreza no longo prazo, os efeitos dos CCTP não são evidentemente ainda mensuráveis no sentido estrito [...] Mesmo entre os partidários da teoria convencional alguns reconhecem que não há resposta às questões relativas aos impactos de longo prazo sobre o bemestar." (p. 498).

${ }^{37}$ Segundo Cortés, Banegas e Solis (2007).

${ }^{38}$ No Brasil, o conjunto das "transferências condicionais de renda” (BPC, aposentadorias rurais e Bolsa Família) teria permitido, de acordo com as estimativas extraídas do Suplemento da PNAD (Pesquisa Nacional por Amostra de Domicílios, enquete em domicílios sobre as rendas e o consumo) de 2006, que o número de indigentes fosse de 21,9 milhões (11,9 \% da população), enquanto seriam de 38,9 milhões (21,3\% da população) na ausência desses programas (o que significa uma diminuição de 44,1\%) (Pochmann et al, 2007, p. 18-21). Para o pobres "simples", os números eram (em 2004) de $31 \%$ com os programas de assistência e de $38 \%$ sem os programas de assistência $(-18 \%)$ 
(desde 2005 nos relatórios anuais). ${ }^{39}$ A adoção desses programas não é, portanto, resultado apenas de uma pressão das instituições internacionais, mas responde amplamente a condições e pressões internas, muito diferentes, em cada caso: calendário eleitoral, explosão social - como na Argentina -, conflitos entre os diferentes níveis de governo, e os governos vigentes parecem buscar, na "caixa de ferramentas" assistencial, o que parece novo, pouco dispendioso e eleitoralmente produtivo. O consenso não é somente internacional, pois ele existe também em cada país: em nenhuma das campanhas eleitorais recentes, os CCTP foram questionados nem pelos partidos, nem pelas Igrejas, nem pela sociedade civil.

As razões da formação desse consenso sobre os CCTP, apesar da ausência de resultados decisivos e mensuráveis em matéria de redução da pobreza, podem ser sintetizadas assim:

1. Paradoxalmente, eles parecem ser melhor focalizados que as políticas ultrafocalizadoras, mas com uma definição um pouco limitada de focalização, ou seja, há poucos "não-pobres" que recebem ajudas. ${ }^{40}$ Em compensação, parece que há muitos "pobres", em torno de um quarto, segundo a maioria das avaliações, que não são be-

39 Por exemplo, em um longo documento sobre o Bolsa Família (Lindert K. et al, 2007), o Banco Mundial não poupa elogios, falando na apresentação do "interesse mundial" por esse "laboratório". Esse documento elogia os responsáveis do Ministério de Desenvolvimento Social do Brasil: "Nós estamos fortemente impressionados pelo seu compromisso, seu profissionalismo e sua excepência técnica. Eles realmente correram uma maratona a passadas de velocista na concepção e implementação do programa Bolsa Família.“ (p. 3).

${ }^{40}$ Segundo os cálculos da CEPAL (2007, p.114) no que concerne às despesas de assistência em geral, para o conjunto dos países da América Latina, 55\% beneficiam os $40 \%$ mais pobres, e $33 \%$ os $20 \%$ mais pobres. Mas, tratando-se dos CCTP, entre 55\% e $60 \%$ das despesas vão para os $20 \%$ mais pobres. A respeito do Bolsa Família brasileiro, o documento citado na nota precedente consagra numerosas páginas à questão da "targeting"/ focalização, para concluir que "o programa Bolsa Família é extremamente bem focalizado”, observando, em especial, que o quartil de rendas mais pobre recebia $80 \%$ das ajudas, e que $85 \%$ dos $20 \%$ entregues indevidamente (the leakages) iam ao quartil seguinte (p. 46). Podemos observar que o outro aspecto da má focalização, ou seja, a proporção de famílias pobres que não recebem a Bolsa Família é abordado em meras quatro linhas nesse documento (p. 47). A busca dos "falsos pobres" parece dominar as preocupações, mesmo se é mencionado que "todos os leakages não provêm da fraude" (idem, nota 78); as fraudes intencionais foram estimadas em $7 \%$ do total dos beneficiários (idem, p. 74). neficiados. Mas isso, de modo geral, é apresentado como um problema técnico de registro, e não como resultado de certas distorções inerentes a esses programas, que fazem com que certas categorias não sejam beneficiadas. Em todos os casos, os beneficiários são famílias, o que faz com que os solteiros sem filhos, ou os idosos isolados, não sejam beneficiados. Além disso, em certos países, a importância da população flutuante e mal registrada (como os refugiados na Colombia, ou os trabalhadores agrícolas no México) faz com que uma importante parte dos "mais pobres" escape a esses benefícios. Enfim, o fato de ser designado publicamente como beneficiário pode gerar uma forte estigmatização (o que pode levar à recusa da ajuda), ou, ao contrário, a designação de "favorecido(a)" pode acarretar fortes tensões, em especial em meio rural.

2. Os CCTP são de baixo custo (de 0,1 a $0,9 \%$ do PIB segundo os países, ou seja, bem menos que, por exemplo, os déficits das aposentadorias públicas) e rendem muito em termos políticos: há um vínculo muito positivo entre extensão desses programas e votos favoráveis ao governo que os implementam. Isso foi particularmente nítido no Brasil no fim de 2006, mas também verdadeiro no Chile e na Argentina. Além disso, eles produzem um importante impacto de imagem no plano internacional.

3. O desestímulo ao trabalho é limitado, essencialmente porque esses programas não tinham por objetivo a reinserção via trabalho. As únicas condições realmente controladas foram as de frequencia escolar das crianças e certos exames médicos (em especial, os exames pré-natais). Aliás, o Banco Mundial, sem poder mostrar os efeitos desses programas em matéria de luta contra a pobreza, felicita seus resultados em matéria de escolarização, antes de qualquer coisa. Os CCTP, portanto, são exitosos porque atingem outros objetivos além daqueles para os quais tinham sido proclamados.

4. Os CCTP libertam os pobres. Todos os programas anteriores de combate à pobreza foram criticados por colocarem os pobres na condição de 
dependência. Os CTTP lhes facultam total liberdade no uso dos recursos monetários repassados. Evidentemente, haveria algumas restrições a relatar, em especial no caso mexicano, já que a transferência do dinheiro às mães remete explicitamente a uma desconfiança do uso que dele poderiam fazer os pais. Mas, de um modo geral, trata-se, de fato, de uma estratégia de empoderamento dos pobres, que está na base do combate à vulnerabilidade. Permite-lhes ter acesso a um nível de recursos que ultrapassa a estrita imposição alimentar, possibilitando realizar escolhas econômicas racionais; a razão e a moral, finalmente, são reconciliadas, já que os pobres podem finalmente mostrar que eles também podem ser homines economici. ${ }^{41}$ No entanto, é impossível medir os efeitos dessa estratégia de empoderamento. As avaliações medem diretamente as melhorias relacionadas às condições de acesso: melhoria das taxas de inscrição e de frequencia escolar em tal ou tal idade; redução dos acidentes de saúde pré e pós-natais. Esses objetivos são moralmente incontestáveis, e a melhoria dos indicadores valida o mérito desses programas. Mas, quando se sai dos serviços diretamente ligados às condições de acesso, as coisas ficam menos claras. É provável que haja uma melhoria das situações mais severas de desnutrição, de má nutrição e de anemia ${ }^{42}$ Mas, uma vez alcançado um patamar mínimo em matéria alimentar, não se sabe ao certo o que os pobres fazem com o dinheiro que recebem. Supõe-se, portanto, que são racionais.

5. Os CCTP produzem uma forte legitimidade. O governo "faz alguma coisa para os pobres", o governo resiste às pressões da área financeira internacional e desenvolve as políticas sociais (como na Argentina); o governo se empenha profundamente na questão de um apartheid mascarado, cujas vítimas são os índios e os reinsere na sociedade (a exemplo do México). Os CCTP

${ }^{41}$ Cf. Braun e Chudnovsky (2005). Os autores desenvolvem a ideia segundo a qual os pobres são preparados para realizar cálculos de custo-benefício racionais.

${ }^{42}$ Valencia (2008, p. 494) menciona 13 estudos nesse sentido, que tratam em especial do México, da Nicarágua, da Colômbia e do Brasil. são, então, apresentados como instrumento privilegiado da coesão social, da formação de um corpo coletivo, que cuida de reincorporar os descamisados, cidadãos sem direitos e sem cidadania, sob a direção benevolente do Estado.

O consenso em torno dos CCTP depende do que se chama, em francês, de um "consenso frouxo". ${ }^{43}$ Ninguém o afirma nem o reivindica; mas observa-se que ninguém é contra esses CCTP. Sua generalização em países em que a renda dos mais ricos é nove vezes mais elevada que a dos mais pobres, longe de ser um ponto de fraqueza, é um argumento em favor do consenso: a excelência técnica e moral dessas políticas encontram ai sua prova. ${ }^{44} \mathrm{O}$ fato de ninguém poder afirmar se o objetivo inicial (a luta contra a pobreza) foi atingido tampouco é um obstáculo, visto que outros objetivos secundários são, pelo menos, parcialmente atingidos (escolarização, saúde) e nenhuma denúncia de efeitos perversos eventuais aparece no cenário público.

Os CCTP não foram implantados sem deliberação. Os meandros dessa deliberação inicial foram, aliás, muito diferentes de um país a outro. No México, o debate sobre a marginalização das comunidades indígenas está na origem do Progresa; no Brasil, o debate sobre a escolarização das crianças pobres e o trabalho das crianças; na Argentina, a questão do desemprego de massa em tempo de crise, etc. No entanto, uma vez que esses CCTP são instalados nesses países e proclamados pelo Banco Mundial, os debates iniciais apagam-se da memória, e o consenso esvazia qualquer contestação ou mesmo deliberação senão aquela que trate da melhoria da eficácia do sistema (leakages)/ a má focalização). Qualquer governo que não instale tais CCTP tomaria, ipso facto, uma posição contra o consenso mundial e teria de se justificar defensivamente. ${ }^{45}$ Qualquer partido de oposição que criti-

\footnotetext{
${ }^{43}$ NE. No original “consensus mou” brando, amorfo, flexível.

${ }^{44} \mathrm{O}$ Chile e a Nicarágua, ambos instalaram CCTP. No entanto, a renda per capita é nove vezes mais elevada no primeiro do que no segundo, e a relação seria a mesma daquela existente entre os PIB per capita na França e no Peru. No entanto, quem ousaria dizer que os instrumentos da política social devem ser os mesmos nesses dois últimos países?

${ }^{45} \mathrm{O}$ único a arriscar isso é a Venezuela.
} 
car os CCTP ver-se-ia imediatamente acusado de "não defender os pobres". O consenso não é feito para libertar a palavra. A era de debates passou.

\section{CONCLUSÕES: consensos sobre as políticas sociais e a democracia}

Voltamos à questão central, a das relações entre o consenso e a democracia. Impossibilitadas de poder desenhar claramente os contornos de uma democracia mundial, as instituições da ONU apresentam uma sucessão das cúpulas produtoras de consenso como um primeiro passo nessa direção. O consenso, assim, seria acompanhado de "um consenso sobre o consenso". Mas esse último não é objeto de qualquer deliberação. Ele se impõe como uma força branda, ${ }^{46}$ que Baudrillard (1991 p.89-90 e p.97) qualificava de integrismo:47 "Vivemos numa sociedade tipicamente integrista, embora simultaneamente em vias de desintegração. Não praticamos o integrismo fundamentalista puro, praticamos o integrismo democrático brando, sutil e vergonhoso, aquele do consenso". E ele qualifica o consenso pelo "grau zero da democracia".

Sem retomar os termos de Baudrillard, Jacques Rancière (2005, p.8 e 10) desenvolve uma posição próxima: "O que o consenso quer dizer, de fato, não é um acordo das pessoas entre si, mas o acordo do sentido com o sentido: um acordo entre um regime sensível de apresentação das coisas e um modo de interpretação de seu sentido. [...] Este consenso diz existir apenas uma realidade, cujos signos devem ser esgotados; um único espaço, mesmo que se tenha que redefinir suas fronteiras; um só tempo, mesmo que se tenha que multiplicar as suas figuras. Por consequencia, ele só exige o nosso consentimento".

O consenso tem uma função ativa: matar o debate e, ao mesmo tempo, submeter aqueles que

${ }^{46} \mathrm{NE}$ : originalmente o autor designa molle.

${ }^{47} \mathrm{NE}$ : este termo se refere geralmente às correntes tradicionais que dizem representar a ortodoxia católica e sua tradição autêntica. Distingue-se do fundamentalismo. Por analogia, pode designar qualquer atitude doutrinal intransigente e conservadora. aderem ao consenso, mesmo sem acreditar muito nele, em nome do "menos pior" ou do "na falta de algo melhor”. Vladimir Jankélévitch (1957, p.184) já dizia que "o unanimismo dos conceitos repousa sobre este duplo pressuposto, otimista e intelectualista, de que o acordo verbal provoca necessariamente o acordo dos pensamentos, tornando quase todas as discussões inúteis; que o acordo dos pensamentos determina, ipso facto, aquele das vontades". Mas, em matéria de políticas sociais, em especial em direção aos pobres, esse unanimismo deixa pairar uma dúvida: "Frequentemente encontramos entre os próprios destinatários dos benefícios um discurso contraditório: eles criticam a natureza assistencial das intervenções públicas, mas, simultaneamente, eles desenvolvem estratégias diversas para se beneficiar destes programas assistenciais, e, provavelmente, no momento de formular suas demandas, eles deixam de lado muitas de suas objeções: 'pouco importa de onde vem a ajuda, o importante é que ela venha". ${ }^{48} \mathrm{O}$ consenso unânime proclamado é, em realidade, dual: de um lado, o acordo sobre o benefício daqueles que ajudam; de outro lado, o acordo dos que são beneficiados em não expressarem seus desacordos a respeito da ajuda. Por trás de suas pretensões democráticas, o consenso tem, então, uma função hegemônica: já que vocês não manifestaram oposição (quem cala consente), isso significa que vocês aceitam tudo, aquém e além do acordo. Portanto, vocês não têm mais nada a dizer (quem consente não fala).

O consenso gera, então, uma série de divergências, ${ }^{49}$ que, por definição, ele não pode reconhecer a existência: já que o pobre (indivíduo ou

${ }^{48}$ Lumi et al (1992, p.11). Na conclusão a respeito da "percepção muito particular da política como prática" dos assistidos, esses autores acrescentam: "um certo pragmatismo aconselha que, face a tantas promessas não-cumpridas, convém exigir dos políticos que eles 'paguem' adiantado o apoio político que solicitam”. (p.157)

${ }^{49}$ Jacques Rancière (1995, p.14) diferencia o desentendimento da divergência: "Aonde a filosofia encontra a poesia, a política e a sabedoria dos negociantes honestos, ela deve tomar as palavras dos outros para dizer que ela diz algo completamente diferente. É nisso que há desentendimento e não apenas divergência, dependendo de uma simples explicação do que a frase do outro diz e que o outro não sabe [...]. Ele [o desentendimento] concerne menos à argumentação do que ao argumentável, à presença ou à ausência de um objeto comum entre um X e u Y".Ver também o capítulo "Démocratie ou consensus" (p.133-165). 
país) aceita a ajuda, só lhe resta aceitar tudo o que ela envolve (a moral da compaixão; a técnica da focalização; a correção das fraudes, etc.). A afirmação da existência de um consensoé,ipso facto, aquela da prevalência de uma "mutual gains approach"/ "abordagem de ganhos mútuos". Contestando o consenso, como filosofia e como método, e em seu conteúdo, fica-se fora do jogo em todos os planos: no plano da ética, em primeiro lugar. Quem gostaria, de fato, de semear a discórdia sobre o que todos os participantes afirmam seu acordo e o caráter racional e subjetivamente consentido das concessões que eles fizeram? Em seguida, no plano filosófico: quem ousaria contrariar um consenso que baseia a sua legitimidade sobre um constante apelo aos direitos humanos, ${ }^{50}$ e onde o direito e a moral estão unificados?. No plano da eficácia técnica, em terceiro lugar: a elaboração do consenso é talvez mais onerosa (em tempo e em pagamento de consultores), mas a eliminação dos conflitos posteriores compensa isso, e muito além disso. Enfim, no plano da harmonia das relações sociais, no consenso não existem perdedores e ganhadores, mas maiorias triunfantes e minorias desgostosas. Só existiriam ganhadores, já que os perdedores eventuais apenas usam as palavras dos ganhadores. O consenso condena a divergência, que deve ser ocultada.

A emergência das técnicas de consensus building depende, de fato, do encerramento no "habitáculo da servidão", 51 de acordo com a expressão de Max Weber. Essa servidão, como qualquer efetiva servidão, é voluntária. O acordo coletivo das vontades não é apenas um produto da servidão: ele é, ao mesmo tempo, o pressuposto, o motor e o seu resultado. Não há nem dominantes nem dominados. É o corpo coletivo conflitivo anterior que foi submetido; e o novo corpo consensual que é liberado. Se, como afirmam os dicionários, consenso é sinônimo de acordo, é preciso tomar

${ }^{50}$ Ver, a respeito, Destremau (2009).

${ }^{51}$ Max Weber, no capítulo 9 (Sociologia da dominação) da Economie et Société (1922, edição francesa, t.2, p.336), qualificava a burocracia como "habitáculo da servidão dos tempos futuros”. essa palavra no sentido musical. Neste caso, o conjunto dos acordes produz a harmonia.

(Recebido para publicação em dezembro de 2009) (Aceito em junho de 2010)

\section{REFERÊNCIAS}

BANURI, Tariq. Translating Ideas into Action-Building a Global Consensus on Climate and Development. Estocolmo: Stockholm Environment Institute, January, 2008.

BAUDRILLARD, Jean. La guerre du Golfe n'a pas eu lieu. Paris: Galilée, 1991.

BID/PNUD/CEPAL/WB. Political consensus building: The Brasilia International Conference on the Millennium Development Goals. In: Latin America and the Caribbean", Brasilia: BID/PNUD/CEPAL/BM, 2003.

BRAUN, Miguel; CHUDNOVSKY, Mariana. Transferencias condicionadas en efectivo como estrategia de reducción de la pobreza: un estudio comparativo en América Latina, In: Dialogo Regional de política. Red para la reducción de la pobreza y la protección social. Washington D.C.: BIDBanco Interamericano de Desarrollo, 2005.

BURGUESS, Heidi; SPANGLER, Brad. Conflict and disputes. The conflict resolution Information source", CRInfo, University of Colorado, Colorado, version IV, july 2003.

CEBALLOS, Marco; LAUTIER, Bruno. Les politiques de transfert conditionnel de revenu en Amérique latine: "Ciblage large" ou émergence d'un droit à l'assistance? In: COUFFIGNAL, Georges (Org.). Amérique latine 2007Les surprises de la démocratie, Paris: La Documentation Française, 2007.

CEPAL. Comisión Económica para America Latina y el Caribe. Panorama social de América Latina 2007. Santiago do Chile: CEPAL, 2007. Disponível em www.cepal.cl/ publicaciones.

Panorama social de América Latina 2009. Santiago do Chile. CEPAL/Nações Unidas. Disponível em www.cepal.cl/publicaciones.

COLLIER, Paul. Consensus-building, knowledge and conditionality. Washington: The World Bank, 2000. Disponível em http://siteresources.worldbank.org/ INTABCDEWASHINGTON2000/Resources/collier.pdf

COOPER RAMO, Joshua. The Beijing Consensus. London: Ed. Foreign Policy Centre, 2004.

CORTÉS, Fernando; BANEGAS Israel; SOLIS, Patricio. Pobres con oportunidades, Mexico 2002-2005. Estudios Sociológicos, n. 72, p. 3-40, 2007.

DESTREMAU, Blandine. Les droits sociaux à l'épreuve des droits humains: les limites de la solidarité internationale. In: BORGEAUD-GARCIANDIA, Natacha; LAUTIER, Bruno; PENAFIEL, Ricardo; TIZZIANI, Ania (Orgs.) Penser le politique en Amérique latine - La recréation des espaces et des formes du politique. Paris: Éditions Karthala, 2009.

FIZBEIN, Ariel;SCHADY, Norbert. Conditional Cash Transfers - Reducing Present and Future Poverty. A World Bank Policy Research Report. Washington D.C., 2009. 363p.

DOISE, Willem e MOSCOVICI, Serge.Dissensions et consensus. Une théorie générale des décisions collectives. Paris: PUF, 1992. 
FILGUEIRA, Fernando.Welfare and Democracy in Latin America: The Devolopment, Crises and Aftermath of Universal, Dual and Exclusionary Social States. UNRISD Project on Social Policy and Democratization Working Document. Genève: UNRISD, 2005.

GOLDIN, Ian; HALSEY, Rogers; STERN, Nicholas. A case for aid: building consensus for development assistance. Washington, DC.: The World Bank, 2002.

JANKELEVITCH, Vladimir. Le je-ne-sais-quoi et le presque-rien. Paris: PUF, [1957]. Reedição: Paris: Points/ Seuil, 1981.

LAIR, Richard. Le consensus en psychologie sociale. In: LETOURNEAU, Alainet; LECLERC, Bruno. Validité et limites du consensus en éthique. Paris: Ed. L'Harmattan, 2007.

LAUTIER, Bruno. Qui ne dit mot consent - qui consent ne dit mot. Remarques sur l'usage du mot "consensus" dans les sciences sociales du développement. COLLOQUE LES MOTS DU DEVELOPPEMENT: GENESE, USAGES, TRAJECTOIRES. Université de Paris-Dauphine, 13-14 novembre 2008. [ no prelo em Economie et Institutions , $\left.\mathrm{n}^{\circ} 1,2010\right]$.

LINDERT, Kathy; LINDER Anja; HOBBS, Jason; BRIÈRE, Bénédicte de La. The Nuts and Bolts of Brazil's Bolsa Familia Program: Inplementing Conditional Cash Transfers in a Decentralized Context. Social Protection Discussion, Paper no. 0709, Washington: The World Bank, maio, 2007. 144 p.

LUMI, Susana; GOLBERT, Laura; FANFANI. Emilio. La mano izquierda del Estado - La asistencia social según los benficiários. Buenos Aires: ed. Miño y Davila-Ciepp, 1992

MARTEL, Pierre. Le mot consensus: origine, sens et emplois dans la langue française. In : LETOURNEAU, Alainet; LECLERC, Bruno. Validité et limites du consensus en éthique. Paris: Ed. L'Harmattan, 2007. p.19-29.

POCHMAN, Marcio; ABRAHÃO, Jorge; CARDOSO, José Celso; SOARES; Sergei (Coords.) PNAD 2006, Primeiras Análises - Demografia, educação, trabalho, previdência, desigualdade de renda e pobreza. Brasilia/Rio de Janeiro:IPEA, setembro, 2007.
PRZEWORSKI, Adam. Democracy and Development. Political institutions and well-being in the world, 19501990. Cambridge: Cambridge University Press, 2000.

RANCIÈRE, Jacques. La mésentente. Paris: Ed. Galilée, 1995. Chroniques des temps consensuels. Paris: Seuil. 2005

SERRA, Narcis; STIGLITZ, Joseph (Orgs.) The Washington consensus Reconsidered. Towards a new global governance. London: Oxford University Press. 2008.

SOMAVIA, Juan. Préface à Les normes internationales du travail- un patrimoine pour l'avenir - Mélanges en l'honneur de Nicolas Valticos. Genebra: OIT, 2004.

SUSSKIND, Lawrence; FIELD, Peter. Dealing With an Angry Public: The Mutual Gains Approach to Resolve Disputes. New York: The Free Press, 1996.

; MCKEARNAN, Sarah; THOMAS-LARMER, Jennifer. (Orgs). The Consensus Building Handbook: A Comprehensive Guide to Reaching Agreement. Thousand Oaks, CA: SAGE. 1999.

CRUIKSHANK, Jeffrey L. Breaking Robert's Rules: The New Way to Run Your Meeting, Build Consensus, and Get Results, Oxford University Pres, 2006.

UNFPA. United Nations Population Fund. State of World population 1999- Six billion, a time for choices. New York: UNFPA, 1999.

VALENCIA, Enrique. Conditional Cash Transfers as Social Policy in Latin America: An Assessment of their Contributions and Limitations. Annual Review of Sociology, v. 34, p. 475-499, 2008.

VAN DEN OEVER, Pietronella. La recherche du consensus dans la gestion des ressources naturelles. Washington D.C.:Banque Mondiale, Avril, 2004.

WEBER, Max .Economie et Société (Edition française: Plon, t. 2 [1922].

WORLD BANK. International Bank for Reconstruction and Development. Global Monitoring Report 2005. Millenium Development Goals: from consensus to Momentum. Washington D.C.:The World Bank, 2005. 


\section{IS THE CONSENSUS ON SOCIAL POLICIES IN LATIN AMERICA THE DENIAL OF DEMOCRACY?}

\section{Bruno Lautier}

For half a century, social policies in Latin America were characterized by conflict. Well, for the last fifteen years the conflict approach gave place to the consensus one, whether the latter relates to goals (of poverty reduction) or the instruments used for this. This paper examines the origins of the expansion of consensus theories, first in the United States, and then in international organizations (UNDP, World Bank ...), and examines in depth a particular case, the consensus built around the Conditional Cash Transfer Programmes as a privileged way (compared to the "focused policies) to fight poverty. Contrarily to what argue the advocates of consensus, who see it as a "mutual gain" mode of decision, this paper defends the view that the widespread search for consensus leads to the extinction of democracy.

KEYwords: consensus, conditional cash transfer programmes, consensus building, democracy, social policies.

\section{LE CONSENSUS SUR LES POLITIQUES SOCIALES EN AMÉRIQUE LATINE, NÉGATION DE LA DÉMOCRATIE?}

\author{
Bruno Lautier
}

Pendant un demi-siècle, les politiques sociales en Amérique latine ont été caractérisées par le conflit. Or, depuis une quinzaine d'années, le conflit a fait place au consensus, que celui-ci porte sur les objectifs (réduire la pauvreté) ou les instruments utilisés. Cet article analyse les origines de cette montée en puissance des théories du consensus, aux Etats-Unis d'abord puis dans les organisations internationales (PNUD, Banque Mondiale...), et développe un cas particulier, celui du consensus autour des Conditional Cash Transfer Programmes comme moyen privilégié (face aux "politiques ciblées") de la lutte contre la pauvreté. Contrairement à ce qu'affirment les défenseurs du consensus, qui y voient un mode de décision "gagnantgagnant", la conclusion de cet article défend la thèse selon laquelle la généralisation de la recherche du consensus conduit à l'extinction de la démocratie.

Palavras-Chave: consensus, conditional cash cransfer crogrammes, consensus building, démocratie, politiques sociales.

Bruno Lautier - Doutor em Economia pela Universidade Paris-Dauphine. Professor de Sociologia do Institut d'Etude du Développement Economique et Social (IEDES) da Universidade Paris 1, Panthéon-Sorbonne. Coordenador do Programa Politiques publiques, vulnérabilités, inégalités, Universidade Paris 1-IEDES. Desenvolve pesquisas na área de: Sociologia das políticas públicas, especialmente da América Latina; análise das políticas de luta contra a pobreza e as desigualdades; estudos sobre a economia informal e o trabalho precário. Suas mais recentes publicações são: "Qui ne dit mot consent - qui consent ne dit mot- Remarques sur l'usage du mot "consensus" dans les sciences sociales du développement”, Economie et Institutions , sept. 2010. Em co-edição com Borgeaud-Garciandia N., Peñafiel R., Tizziani A.(Org.): Penser le politique en Amérique Latine ...., (Ed. Karthala, 2009), e com Cartier-Bresson Jean, Destremau Blandine.'Les mots du développement: trajectoires et pouvoirs”, In: Revue Tiers Monde (n. 200, oct. dec. 2009). 